\title{
News Items About Negroes in White Urban and Rural Newspapers
}

\author{
IRA B. BRYANT, JR.
}

\section{Purpose of the Investigation}

The purpose of this investigation is to show the general characteristics of the Negro news items that appear in the white urban and rural newspapers of Texas, and to determine what customs, traditions and community mores are reflected through the newspapers of a particular locality in regard to Negroes. Further, this investigation is to show by comparison the difference in the methods of writing Negro news in the white urban and rural papers, and to determine if the Negro's political status bears any relation to the methods of presenting Negro news that might appear in the columns of the newspapers.

Since the coming of the Negro to America in 1619, numerous social problems have arisen from the attempted adjustment of the two groups (white and Negro) in the same environment. Various sections of the country have their race problems, but the problem seems far more acute in the South than in other sections of the country. This condition may be due to the fact that, in $1920,85.1$ per cent of the total Negro population resided in this section of the country. In some sections of the country, the method of solving the problem emphasizes interracial cooperation; in others, an open vigorous policy of racial oppression is carried on. In still other sections, there is a tendency to em- phasize news that places the Negro in an unfavorable light. Unfortunately, many whites get their only impression of Negro life through the press. Certainly, if the Negro is played up as being ignorant, without high standards, dishonest, and inherently antisocial, definite attitudes will be formed in regard to him by the white readers and will in time become conventionalized and customarý. So different localities present different problems, and therefore afford an opportunity for different solutions. The common problem as it has been expressed by Wolfe, "is the mutual, social, industrial and political adjustment upon the same soil of two races between whom the difference in color is perhaps the most superficial of the distinctions which divide them." Far more fundamental than the difference in color is the desire to develop and maintain social caste and group distinction.

The caste system had its origin during the period of slavery when an attempt was made to fix permanently the status of the Negro in the social order of the South. Various means of subjection were employed to obtain this end. In his attempt to adjust himself to his strange environment, and to a new culture, the Negro developed many peculiar character traits. The primary contacts of the

1 A. B. Wolfe, Readings in Social Problems, p. 677 . 
two races during those days of slavery caused the Southern white people to form definite attitudes toward the Negro. Many of the attitudes that originated during the period of slavery are today customs accepted uncritically by the masses of Southern white people. These customs or vestiges of a past culture are kept alive by the newspapers and other agencies of communication.

Negroes in general feel that the newspaper is one of the means through which these customs are passed on from generation to generation, thereby acting as an organ of propaganda for the system of social caste. Any attempt to show why some of the newspapers of Texas have adopted a characteristic style in the presentation of Negro news has been purposely avoided in this investigation. Rather, an attempt is being made to present the facts that appear and set off news as Negro news.

There are a number of widespread stereotypes about the Negro's traits of character entertained by Southern white people. Some of the more common beliefs concerning the Negro's traits of character are that he is habitually a criminal, that he is shiftless, superstitious, happy-go-lucky, childish, excitable, mentally inferior, lazy, immoral and unmoral. ${ }^{2}$ It is thought that these beliefs which are reflected from time to time in the local newspapers differ from community to community, being dependent upon local differences in experience and customs. Negroes think that the expressions of these beliefs through newspapers are subtle in mo-

${ }^{2}$ K. Young, Source Book for Social Psychology, p. 516. tive and designed as repressive measures "to keep the Negro in his place." This may or may not be the motive of the newspapers in maintaining this policy in printing Negro news but the methods employed by the Southern papers in presenting Negro news have developed characteristics which label news items as Negro news. To isolate these characteristics is one of the aims of this investigation. Thus, specifically, this investigation is concerned with the types of Negro news that appear most frequently, the characteristic style of describing the Negro, his manner of speech when he is quoted; it will also attempt to determine the difference, if any, in the treatment of news items concerning the professional and non-professional Negro. In addition, the study will tabulate the frequency of such references and usages as the use of the Negro's first name instead of the surname; the reference to the Negro man as "boy" and the identification of Negroes by such terms as "nigger," "darky," and "dusky."

To some these usages may appear inconsequential for the most part. But Moton has expressed the prevailing opinion among Negroes when he says: "They are gravels in the Negro's shoe, small in size but capable of inflicting great discomfort and impeding progress." 3 Furthermore, those who have lived and travelled in the Southland will no doubt understand the significant part played by such apparently inconsequential customs in the general relationships of the races. Moreover, those who follow the Southern newspapers will probably p. 5 . 
agree that while the customs therein depicted may differ, the general method of disseminating them is much the same. There are some papers, however, that do not make a general practice of presenting the Negroes who appear in their columns in an unfavorable light, but on the contrary, carry a large amount of news pertaining to the cultural activities of $\mathrm{Ne}$ groes. It appears likely that the policies of these papers may be affected by the improved political and occupational status of the Negro in these cities and communities. It is one of the aims of this study to test this hypothesis. So this investigation will not be confined to the types of news that picture the Negro as having undesirable character traits, but will also include those types which depict policies of tolerance and good will.

There appears to be a noticeable difference in the methods of writing Negro news in the urban and rural white newspapers of Texas. The urban newspapers, for the most part, seem to have adopted a characteristic manner in the presentation of Negro news, in playing up the Negro's antisocial behavior, and in presenting Negro news items which reflect attitudes of contempt of whites toward Negroes and also a feeling of superiority in their relationship with the Negro. On the other hand, while some of these characteristics are common to the rural papers, the general policy of the rural papers seems to promote racial cooperation and good will. In Negro circles numerous theoretical reasons are offered to explain the cooperation that exists between the Southern rural whites and rural Negroes. Chief among these reasons is the attempt to curb the steady flow of rural Negroes to the urban centers. It is not the purpose of this study to evaluate this theory, but rather to point out by comparison the differences in the methods of writing Negro news by the urban and rural newspapers of Texas.

The final phase of the problem with which this investigation will be concerned will be the comparison of the methods of writing Negro news appearing in the newspapers of today with the methods of writing Negro news that appeared in the newspapers of twenty years ago (1912). The significance of this problem lies in the conclusions reached in determining the difference in the methods of writing Negro news by the Texas white newspapers of these periods. The comparison of these groups of papers should indicate one of three trends: That the policy of the white papers of today in presenting Negro news has become more liberal than the papers of twenty years ago; or that the white papers of today are less liberal in their treatment than the early papers; or that the papers of today do not indicate that a noticeable change in the methods of writing Negro news has taken place during this period.

The major problems of this investigation, then, will be: First, what are the types and characteristics of Negro news items that appear in the urban and rural white newspapers of Texas? Second, is the method of writing Negro news affected by the Negro's political status and occupational status in his community? Third, is there a noticeable difference in the methods of presenting Negro news that appears in the urban and rural 
newspapers of Texas? Fourth, are the methods of writing Negro news appearing in the white papers of today any different from that which appeared in the papers of twenty years ago (1912).

\section{General Procedure}

The data for this investigation were secured from twenty-eight newspapers, sixteen urban and twelve rural, covering a period of thirty and sixty days respectively. ${ }^{4}$ Each of the following urban papers was selected on the basis of its circulation and of the city population. The papers were: The Austin American, the Beaumont Enterprise, the Dallas News, the Dallas Dispatch, the El Paso Herald, the El Paso Times, the Fort Worth StarTelegram, the Fort Worth Press, the Galveston News, the Houston Chron$i c l e$, the Houston Press, the Houston Post, the Port Arthur News, the San Antonio Express, the San Antonio Light, and the Waco News. The cities were located so as to represent the different geographic sections of the state. The twelve rural papers were selected on the basis of community population (the limit was not to exceed 5,000$)^{5}$ and the density of Negro population. The following papers were selected: The Athens Review, the Ballinger Ledger, the Bay City Tribune, the Caldwell News, the Commerce Journal, the Cuero Record, the Dalhart Texan, the Edinburg Review, the Lampasas Leader, the Marshall Messenger, the Timpson Times, and the San Jacinto Times from Coldspring, Texas. The papers of 1912 that were

\footnotetext{
- February and March-1932. tion.

$\checkmark$ The Marshall Messenger is an excep-
}

selected were as follows: the Austin Statesman, the Beaumont Enterprise, the Fort Worth Record, the Galveston News, the Houston Chronicle, the Houston Press, the Houston Post, the San Antonio Express, the Ballinger Ledger, and the Cuero Daily Star.

During the period of investigation, 918 current newspapers were examined, and all items concerning the Negro were classified under one of two headings, primary and secondary. Primary, in this investigation designates those items in which the Negro appears to be the principal character or one of the principal characters. By secondary is meant those items in which the Negro appears only incidentally in the event discussed. The 468 urban papers yielded 597 primary and 70 secondary items. The 450 rural papers yielded 220 primary and 17 secondary items. The classification further revealed that the news items could be divided into three main divisions, social, antisocial and neutral. Anti-social news included all news that pertained to criminal offenses. The term "social" is applied to those news items concerned with the activities of individuals, organizations, and institutions relating to constructive subjects such as education, arts, business, or sports. The term "neutral" is applied to those news items that could not be placed in the social or anti-social categories, such as records of births, human interest stories, and news of a general nature.

\section{Types and Methods of Writing Negro NeWs}

During the period of investigation the urban papers yielded 2,523 inches 
of Negro news, while the rural papers yielded 1,092 inches of Negro news. This amount did not include paid advertisement. The significant difference between the types of news that appeared in the urban and rural papers concerning Negroes lies in the quantity of social news as compared with the quantity of anti-social news. The space devoted to anti-social news items comprised 84.4 per cent of all Negro items appearing in the urban papers against 12.8 per cent in the social category and 6.6 per cent neutral. On the other hand, the rural papers devoted 24.5 per cent of the total space given to Negro news to be amiss to conclude in the light of these figures that the constant playing up of these types of news by the urban and rural papers may cause such beliefs to be formed concerning the Negro's traits of character as: that Negroes are morally weak; that they have a natural disposition to sexual crimes and crimes of violence; that they are naturally addicted to petty thefts and emotionality.

The phase of the investigation dealing with the methods of writing Negro news revealed that there are certain characteristics peculiar to Negro news items, namely the racial identification of the principal char-
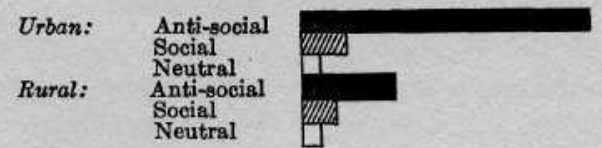

Figure 1.-The Amount of Space Given to Anti-Social, Social and Neutral News in the Urban and Rural Papers.

that of his cultural activities, and 59.8 per cent to that of an antisocial nature, and 15.7 per cent neutral, as shown in Figure 1. The average percentage of anti-social and social news was 78.3 and 13.1 per cent, respectively, for each urban paper. For each rural paper the average percentage of anti-social and social news was 62.8 and 30.6 respectively. Seventy-one per cent of the anti-social Negro news in the urban papers could be grouped under the following classifications: Attacks on women, liquor charges, thefts, robberies, and murders. More than 67 per cent of the anti-social news in the rural papers could be grouped under the same classifications. It would not acter in the headlines; the frequent use of the Negro's first name instead of the surname; picturing Negroes as using a dialect and the omission of the titles of Mr., Mrs., and Miss in connection with the names of Negro men and women. This phase of the investigation also pointed out the use of the terms "nigger," "darky" and "dusky" by the papers studied. Much space was given to items that might substantiate the beliefs among Southern white people that Negroes are superstitious, simple, ignorant, childish, clown-like, sincere believers in the power of a rabbit's foot, voodoo and fortune tellers of the most absurd type. The chief objections to items attempting to reflect 
such characteristics has been that the white papers have made these traits racial rather than individual marks.

\section{The Effect of the Negro's Political Status on Negro News}

To determine the effect of the Negro's political status on the types and methods of writing Negro news, two papers were selected for investigation. They were the Galveston News and the Houston Chronicle published in cities whose geographic location and population compositions appear quite similar, the chief difference be- placed undue emphasis on certain anti-social activities of the Negro, such as robbery, attack, theft and murder, while this same classification shows that the Galveston News only emphasized to a great extent one type of anti-social news, which was murder. However, the police records indicate a close similarity in the per cent of arrests during this same period. Other types of anti-social news appeared to have been well balanced as to the amount of space devoted to each. The types of news that appeared in the Galveston News was undoubtedly affected by the appearance of the pro-
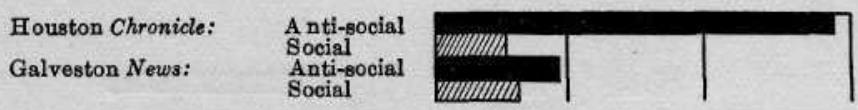

Figure 2.-The Amount of Space Given to the Negro's Anti-Social and Social News in The Houston Chronicle and Galveston News.

ing the franchisement in one (Galveston) and the disfranchisement of the Negro in the other (Houston). Figure 2 presents a comparative picture of the amount of social and anti-social Negro news that appeared in these papers during this investigation. Figure 2 indicates that of the 159 column inches devoted to Negro news items by the Galveston News, 36.4 per cent of the total was given to the Negro's social activities and 58.4 per cent and 5.2 per cent were devoted to anti-social and neutral respectively. On the other hand, The Houston Chronicle devoted 344 column inches to Negro news items, but only 7.2 per cent of this space was concerned with social news while 86.9 per cent and 6.9 per cent were given to anti-social and neutral items.

The classification of the news items indicated that the Houston Chronicle fessional Negro in the columns of this paper.

It was possible in some of the news items to determine if the Negro was a professional or non-professional. This condition did not obtain in all of the items. There are only 228 professional Negroes in the city of Galveston, ${ }^{6}$ which is only 19.6 per cent of the professional Negroes in Houston; yet ten times more professional Negroes appeared in the news items of the Galveston News than in the news items of the Houston Chronicle. There are 1,161 professional Negroes in Houston, yet the activities of only five of this group made news material for this paper.

The fact that the professional Negroes of Houston do not appear in the news items of the white papers,

6 U.S. Census-Texas Population Bulletin 1930 . 
while not surprising, may be due to the following factors: First, since the Negro is not actively engaged in politics there are no recognized political leaders who might place local issues before the race; second, the Houston Negroes put forth little effort to get their activities in the white papers, since there are three Negro weeklies available.

Both of these papers, like other Southern papers are prone to identify the principal character of the news items concerning the Negro by emphasizing his racial identity in the headlines of the item. It was interesting to note that the Galveston paper identified the Negro in some instances by using the term colored which was not used by the Houston Chronicle. It was further observed that the Galveston paper did not reveal a single instance where the Negro was referred to by his first name, while the Houston Chronicle referred to Negro men and women by their first names in 39 instances.

The use of the terms, Mr., Mrs., and Miss, when referring to Negroes is not customary in the South. Thus the use of the terms occurred in only three instances in all the urban papers investigated and two of these instances may be accounted for in the Galveston News. The use of these terms was probably offset by the Galveston News with the use of professional titles which occurred in connection with the Negro's name in ten instances. The Houston Chronicle did not use either of the terms, $M r$., Mrs. and Miss, or a professional title in connection with names of Negroes.

The use of the terms "nigger," "dusky" and "darky" which are considered in Negro circles as oppro- brious were not found to be used in the Galveston paper very frequently. On the other hand, in the Houston Chronicle the term "nigger" was used four times while "darky" appeared twice. These figures might suggest that the Galveston paper is more considerate of its Negro patronage than the Chronicle. If this is true, it is significant in that newspaper competition is much keener in Houston than in Galveston. The Houston Negroes have their ehoice of three white dailies and three Negro weeklies while the Negroes of Galveston have only one white daily and one Negro weekly, but in spite of this fact, the Houston white dailies refer to the Negro in terms of "nigger," "darky" "boy," "dusky," "big burly" and other terms with a much greater frequency than the Galveston paper. It is significant to observe that the Negro woman appeared in the Galveston News ten times, but not once was she referred to as a "negress." On the other hand, the Negro woman appeared in the Houston Chronicle twelve times and was referred to as a "negress" in nine instances.

It is probable that much of the data presented in comparing the methods of writing Negro news by these papers may be due to chance but comparing the newspapers as a whole, it was interesting to note that the contrast between the treatment of Negro news by five papers taken from three cities, where Negroes are disfranchised, and eleven papers published in seven cities, where Negroes are permitted to participate in the election of local officials, is even more striking than that whicin was pointed out in the Galveston News and the Houston Chronicle. The investigation 
revealed that the five papers, taken from the cities where Negroes are not permitted to vote in the city elections, are more likely to make use of opprobrious references than newspapers published in cities where the Negro participates in the local election. The data suggest that the papers published in cities where the Negro is permitted to vote are attempting to promote a policy of good-will and friendly relations between the races by minimizing the use of "customary" references to Negroes who appear in their columns.

\section{The Influence of the Negro's Occupational Status and Num- BER IN THe TOTAL PopU- LATION ON NEgRO News}

An attempt was made to determine the possibilities of the Negro's occupational status and the number of Negroes in the total population of a city or town affecting the types and treatment of Negro news. Conclusions were drawn from general deductions, based on an analysis of the Negro's occupation in the cities and towns from which papers were taken, during this investigation. The Negroes in the urban centers are engaged in a large variety of occupations, with an overwhelmingly large number occupied at menial tasks listed under the classification of common and semiskilled labor. A large percentage of Negro workers are engaged in the following eight occupations: building industry, manufacturing, transportation-communication, steam and street railroad work, chemical and allied industries, wholesale and retail trade (porters and delivery), slaughter and packing, and domestic personal serv- ice. $^{7}$ The percentage of Negroes engaged in the first seven of these occupations varies considerably, being affected by the geographical location of the city. But it can be easily observed from Table I that the percent-

\section{TABLE I}

The Percentage of Negro Workers Ten Years of Age aNd Over ENGAGED IN DOMESTIC AND Personal Service

\begin{tabular}{lc}
\hline \hline City & Per Cent \\
\hline Austin & 47.5 \\
Beaumont & 30.6 \\
Dallas & 43.5 \\
El Paso & 39.4 \\
Fort Worth & 40.4 \\
Galveston & 33.3 \\
Houston & 34.7 \\
Port Arthur & 36.9 \\
San Antonio & 78.0 \\
Waco & 51.6
\end{tabular}

age of Negroes engaged in domestic and personal service in each of these cities is surprisingly alike. Domestic and personal service includes butlers, waiters, cooks, maids, chauffeurs, yard-men, laundresses and others engaged in household duties. As these figures clearly show, a large percentage of the Negroes in these cities are employed in this field. Any group that earns its living as a servant to another is generally treated as an inferior group as a whole by the dominant group. Especially are those who hire themselves as domestic and personal servants accorded the treatment of boys and girls. The customs formed out of conditions of this kind are generally expected to be reflected in the newspapers and other agencies of communication. These facts suggest that the Negroes of these cities are economically at the mercy of the white people since they own no

${ }^{7}$ U.S. Bureau of Census-Texas Population Bulletin 1930. 
factories and control no banks. Since this is true, it is evident that most of the jobs held by the Negroes of these cities are controlled by white people and the Negro is in no position to demand fairer treatment from the newspapers.

The greater percentage of rural Negroes are engaged in agriculture. This condition probably affects the type of news appearing in the rural newspapers concerning Negroes. To be sure, the rural Negro is not economically independent, as many Negro farmers fall in the tenant class rather than in the land-owning class. ${ }^{8}$ Even so, he is less dependent economically than the urban Negro. As an agriculturist the rural Negro becomes a producer rather than a job seeker, and therefore he is not a keen industrial competitor of the white man as the urban Negro. These conditions therefore lessen the necessity of prejudicing the public mind against the Negro. No data were available as to the percentage of rural Negroes engaged in domestic and personal service. The general types of occupations in which the rural Negro is engaged does not suggest that he is in a position to demand any courtesies from the rural newspaper. But the difference in the type and treatment of the news in the rural and urban papers concerning the Negro perhaps lies in the fact that the present practices are used to curb certain social developments that tend to threaten the existing social order, while as yet these conditions are unfamiliar to rural life.

Among the multiplicity of factors that influence the type and treatment

${ }^{8}$ E. B. Reuter-The American Race Problem, p. 235. of Negro news is a fairly widespread idea that the policy of the white newspapers is directly affected by the number of Negroes in the community. If the number of Negroes is large the repressive measures are stringent and the lines of segregation are more numerous. On the other hand, if the number of Negroes in the community is small in proportion to that of the whites, the Negroes are allowed more freedom, are hardly segregated at all and their activities that make news are for the most part no different from those of any other racial group. It is probable that the general relationship between the races (Negro and white) in a city or community is affected by the number of Negroes in the total population but the data of the investigation do not support the theory.

\section{Methods of Writing Negro News BY THE PAPERS OF 1912}

Previous data indicate that the treatment of Negro news by the white press is colored with definite characteristics that label news items as Negro news. These characteristics suggest certain community customs prevalent among white readers. A common belief among Negro leaders is that the characteristics depicting unfavorable policies of the Texas white press toward Negroes have decreased with the years, and if the general policy of the press was properly measured, it would probably show that a slow but steady change has taken place, for the better, in the methods of writing Negro news. Insufficient data would probably preclude an investigation of this type in Texas, especially in chronological order. 
This phase of the investigation was concerned with the following points: first, racial identity in headlines; second, use of the Negro's first name; third, the use of proper titles; $M r$., Mrs. and Miss; fourth, "negress" and other reference to Negro. It appears from the investigation of the 270 papers (1912) that the policy of labelling Negro news items with the principal character's racial identity is much the same as the policy of the papers of today (1932) with the exception that the newspapers of 1912 used the term "darky" in the headlines when referring to Negroes. Although the term "darky" was used as a term of racial identification in several news items in the current papers, it was not used in the headlines. The practice of referring to Negroes by their first names instead of their surnames appeared to have been more frequent in the newspapers of twenty years ago than in the papers of today. The newspapers of 1912 as the papers of today yielded no evidences of the tendency of addressing Negroes who appeared in their columns by their proper titles, $M r$., Mrs. and Miss. Another practice of the papers of 1912 that appears to be on the decline is the use of the term "negress" when referring to Negro women. The Negro woman was mentioned 63 times, 44.4 per cent of the time she was referred toas a "negress." The current urban and rural papers used the term "negress" in 31 per cent of the total number of times the Negro woman was mentioned. These data indicate that the difference in the methods of writing Negro news by the Texas press twenty years ago and the Texas press today is very slight. Since social changes are slow, it is difficult to determine conclusively whether or not there has been any change in the methods of writing Negro news by either the urban or rural papers in the short span of twenty years. However, the data suggest that, while the newspapers of this period, for the most part, carry the same usages, there are evidences that indicate the slow development of a better spirit in the general treatment of Negro news by the white papers of today. The nonuse of the term "darky" in the headlines, and the fact that the terms "wench" and "senegambians" (used in the papers of 1912) were not used in the current items studied are significant changes that have taken place in the last twenty years.

\section{RECOMMENDATIONS}

The conclusions reached on the basis of the data gathered for this investigation suggest the following: First, that the white newspapers of Texas make an effort to adequately present the social activities of Negroes as well as the anti-social. This will go a long way toward the promotion of good will and cooperation that should exist between the white and Negro races. Second, that the white press of Texas discard the use of offensive references when referring to Negroes who appear in their columns. These references are distasteful to their Negro patronage. Third, that the Texas white papers employ at least one Negro reporter to cover the activities of Negroes. Fourth, that the Negroes of Texas make an effort to place their social activities before the white reader through the columns of white dailies. 